\title{
Physical Activity Enhances Self-Esteem of Male College Students; a Randomized Controlled Trial
}

\author{
Ali Kavosi ${ }^{1}$, Masoumeh Saadati ${ }^{1}$, Ali Movahedi ${ }^{1}$, Majid Farahnia ${ }^{1,}$, , Gholamreza Mohammadi ${ }^{1}$, Abolfazl Aghababayan $^{2}$, \\ Amin Asghari ${ }^{1}$, Shervin Assari ${ }^{3,4}$ \\ 1. Neyshabur University of Medical Sciences, Neyshabur, Iran \\ 2. Golestan University of Medical Sciences, Golestan, Iran \\ 3. Center for Research on Ethnicity, Culture and Health (CRECH), University of Michigan School of Public Health, Ann Arbor, USA \\ 4. Department of Psychiatry, University of Michigan, Ann Arbor, USA
}

"Corresponding Author: Majid Farahnia, Masters of Exercise Physiology, Neyshabur University of Medical Sciences, Neyshabur, Iran Email: majidfarahnia@yahoo.com

\begin{abstract}
Introduction: Self-esteem is a sense of values, the degree of approval, affirmation, acceptance and being valuable that a person has toward himself. As exercise causes a feeling of adequacy and efficiency, it may increase self-esteem. The present research aimed to study the effect of a physical activity program on self-esteem of male college students.

Methods: The present study was a randomized controlled trial. The study randomly assigned 90 male college students into two groups of intervention and control. Eight weeks of exercise program were applied to the intervention group and the control group received no intervention. The program was composed of regular aerobic exercises. Before and after the study, self-esteem of the subjects were assessed by using the Copper Self Esteem Scale. The results were analyzed using the SPSS $_{16}$ software. Descriptive statistics (frequency, mean and standard deviation) and inferential statistics (Chi-square test, independent and paired t-test) were applied.

Results: The mean self-esteem of the students in the intervention group changed from $90.6 \pm 9.5$ to $109.8 \pm 5.3$, while it was stable for the control group (91.1 \pm 1.3 to $92.4 \pm 2.1)$. The independent sample's $t$-test showed a statistically significant difference between the level of improvement between the two groups $(\mathrm{P}<0.001)$.

Conclusion: The results indicate that physical activity programs boost the self-esteem of male college students. Considering the ease of implementation, the benefits of physical activity and no serious adverse events, we recommend the use of mild to moderate physical activities as an intervention to enhance self-esteem, a determinant of mental health.

Keywords: Regular Aerobic Exercise, Self-esteem, Students
\end{abstract}

Article History: Received: 2 Mar 2015; Revised: 8 May 2015; Accepted: 15 May 2015

Cite this article as: Kavosi A, Saadati M, Movahedi A, Farahnia M, Mohammadi G, Aghababayan A, Asghari A, Assari S. Physical activity enhances self-esteem of male college students; a randomized controlled trial. Int J Travel Med Glob Health. 2015;3(2):49-52.

\section{Introduction}

Self-esteem is the judgment and ideas that an individual steadily and consistently states about his values or it is the sense of values, the degree of approval, and acceptance and worth that an individual has about himself $[1,2]$. Since selfesteem is one of the most important factors of human development and has significant effects on the mind, emotions, desires, values and goals of a person, an individual whose self-esteem is broken, experiences anxiety, emotional instability, and is suspicious of his shyness and lack of competence of the truth [3]. Studies also show that self-esteem is a major psychological factor affecting health and people's quality of life in the world. Increased self-esteem creates a sense of empowerment and being valuable in the person. Other positive changes appear such as academic achievements, increased efforts to succeed, having high self-esteem, being ambitious and reaching higher levels of health [4].

Exercise causes a feeling of competence and performance that may potentially lead to increased self-esteem [5]. Research shows that regular exercise programs not only improves physical health but also mental health, coping with anxiety and depression and may even increase self-concept and self-esteem [6]. Alfermann and colleagues argued that if societies force people to exercise, it will eventually help enhance self-esteem and the physical and mental health of its people because the athletes have high self-esteem and motivation. All age groups should be encouraged to exercise in different societies [7].

Ghaffari et al. suggests that regular exercise programs may increase self-esteem of students [8]. Considering the ease of implementation, the benefits of physical activity with no serious side effects, they proposed exercise as a means to increase self-esteem and physical and mental health [8]. Sonwany et al. found that self-esteem correlates with positive qualities such as social adjustment, stress, and health-related behaviors [9]. However, some researchers considered self-esteem as reflecting psychological benefits derived from participating in regular exercise [10]. Weiss et al. compared, people who took at least two years of continuous aerobic exercise with non-athletes and found that regular physical exercise can increase confidence and self-esteem because of the habit, the desire to gain victory and reach a goal and stronger muscles [11].

Gabriel and colleagues in a research on mental skills of athletes concluded that mental health variables (anxiety, depression, self-esteem, confidence, positive mood, etc.) have a 
positive relationship with exercise and the effect varies according to individual differences [12].

Due to the type of activity and the role they play as well as the expectations that others have of them and their responsibilities, college students may be more vulnerable than other population groups [13]. The expectation placed on college students is that the substantial investments spent on them from school to higher education will transform them into competent citizens post-graduation. But the undeniable fact is that these investments cannot provide what they expected without concern to the mental health of the community [14]. This study aimed to determine the effect of a physical activity program on self-esteem of male college students.

\section{Methods}

This is a randomized controlled trial performed at the Islamic Azad University of Gorgan in 2012. The study randomly enrolled 90 male college students to either intervention (45 students) or control (45 students) groups.

Participants were selected from dormitories. The aim of the study was first explained by the researchers to the participants and they were ensured that the information is confidential and complete. All data were collected anonymously. All participants provided informed consent.

The enrolment criteria of the study included the male students of the Gorgan University, and have willingness to participate in the exercise program. Students with professional or semi-professional sports history, tobacco addiction or a physical problem or medical disease were excluded. Due to cultural restrictions on women's sports, the training program was only conducted on men.

The data collection included the demographic characteristics such as age, occupation, mother and father's education level, economic status, family and past semester's average. The self-esteem test was used to measure self-esteem. To determine the reliability of the questionnaire, a pilot study was conducted on 10 subjects with confirmed $\mathrm{R}=0.89[15,16]$. The score between 35-70 questionnaires and 71-105 was considered as low self-esteem and self-esteem average, respectively. A score between 106and140, was considered as a high self-esteem level.

A regular exercise program was conducted 3 times a week for 45 minutes during the evening hours and over 8 weeks [8, 17]. The researcher trained the subjects with another researcher and expert assistant in physical education (with a doctorate degree in physical education). Each training session began with stretching and warm-up exercises for 10 minutes with slow running and then continued with intervals of rests for 30 minutes at the end of the session to return to the initial state (cold) some movements were done for 5 min. The intensity of the workout was increased by increasing the duration of running slowly in each session. If samples in 3 sessions or one fourth consecutive training sessions were missed or significant incidents occurred during the 8-week training period or they participated in other sports during the study, were excluded. Fortunately, none of the criteria for removal occurred during this study. Before and after 8 weeks, the Cooper Smith self-esteem test was used to measure and compare the self-esteem of the two groups.

The results were analyzed using the SPSS v.16 software using descriptive statistics (frequency, mean and standard deviation) and inferential statistics (Chi-square test, independent and paired t-test)

\section{Results}

Most students in both groups (56\% for intervention and $60 \%$ for controls) were 18 to 22 years old. The mean age of the intervention and control group was $21.75 \pm 1.52$ and $21.35 \pm$ 1.72 respectively. Most of the research in the intervention group (78\%) and controls (75\%) were undergraduate students. The last semester grade point average (GPA) of study participants indicated that the two groups were not significantly different. The average last semester GPA was (16.7 \pm $1.14)$ and $(17.02 \pm 1.23)$ in the intervention group and the control group, respectively. The results showed that the intervention group (59\%) and controls (62\%) had a medium family economic situation level. Also, 78 percent of the students in the intervention group and $69 \%$ of the students in the control group were interested in sports and exercise.

Chi-square tests did not show a significant difference in age, educational level, GPA, economic status, and interest in sport in the two groups. In other words, the two groups were homogeneous regarding demographic characteristics and other potential confounders ( $\mathrm{p}>0.05)$.

The independent t-test did not indicate the phase significance difference between the two groups before intervention $(p=0.122)$. This is while both groups showed significant differences after the eight week intervention $(p<0.001)$. In other words, regular exercises have been effective on the self-esteem of the intervention group (Table 1).

The result of the comparison of students' self-esteem after a regular exercise program by Paired $t$ test showed that the intervention group showed a significant difference before and after the intervention phase $(\mathrm{p}<0.001)$ while the control group did not show a significant difference $(\mathrm{p}=0.115)$.

Table 1. Comparison of students' self-esteem in two groups before and after regular exercise

\begin{tabular}{|c|c|c|c|c|c|}
\hline \multirow[t]{2}{*}{ Group } & \multicolumn{2}{|c|}{ Intervention } & \multicolumn{2}{|c|}{ Control } & \multirow{2}{*}{ Paired t-test (p-value) } \\
\hline & Mean & SD & Mean & SD & \\
\hline Before intervention & 90.6 & 9.5 & 91.1 & 1.3 & $\mathrm{P}=0.122$ \\
\hline After intervention & 109.8 & 5.3 & 92.4 & 2.1 & $\mathrm{P}<0.001$ \\
\hline Independent $\mathrm{t}$-test & \multicolumn{2}{|c|}{$\mathrm{P}<0.001$} & \multicolumn{2}{|c|}{$\mathrm{P}=0.115$} & \\
\hline
\end{tabular}


The ANOVA test showed that there was no significant association between self-esteem and age, educational level, GPA of last semester and economic status in the intervention group $(\mathrm{p}>0.05)$.

\section{Discussion}

Regular exercise increases male college students' self-esteem. Similar studies have been done in this field. Asci studied the effects of physical exercise on body image and self-esteem and showed that the intervention group had higher self-esteem compared to the control group after exercise [18]. In a study conducted in England by Thomas, eight weeks of aerobic exercise increased self-esteem of the participants [19]. Ghaffari et al. showed that self-esteem scores of students in the intervention group increased from $111.4 \pm 8.1$ to $93.1 \pm$ 8.2 following the intervention [8]. Koruzhadeh et al. also found that the average self-esteem of the subjects in the intervention group increased from $99.2 \pm 9.0$ to $104.3 \pm 7.6$ [20]. However, in a study by Saadatmehr et al. an aerobic exercise program did not have any effect on the elf-esteem of the nurses [21].

Generally, experience and success in every area of human progress, sense of self-worth and ability in any intervention increases self-esteem [22]. Bahaeloo-Horeh and Assari also showed that mountaineering enhances self-esteem of students [23].The negative results in the study by Saadatmehr could be due to the sample size, sample, dose of intervention, or measurement. The nursing profession needs the nurses to have self-esteem, confidence, focus and high power determination to do well in stressful environments such as hospitals, and simple programs. It is more obvious that nurses are not able to overcome the stresses of their work alone and without physical activities [24, 25].

In our study, a significant relationship was found between GPA and self-esteem, where individuals with high self-esteem had a better school performance. Academic achievements and self-esteem have a reciprocal relationship [26, 27]. Self-esteem may lead to increased academic success since the self-confidence and positive attitude learned during exercise may enhance self-confidence and motivation. It is also said that academic success enhances self-esteem in human beings [26, 27].

Our findings have public health implications for the promotion of mental health and also obesity prevention. This is particularly important due to the associations between obesity and mental health problems [28-31] and also the global trends in obesity and mental health problems such as suicide [32-35]. Enhancement of physical activity may improve a wide range of outcomes including mental health and obesity of populations [36-39]. The promotion of physical activities may have spillover effects in other domains [40-43]. Fortunately, there are state of the art and evidence-based interventions that enhance physical activities [36, 44-47].

\section{Conclusion}

College students are susceptible to stress and mental pressure [48]. Regular exercise increases the self-esteem of male college students. Considering the acceptability and feasibility of the program, the benefits of the promotion of the physical activity [36-39], and no serious side effects, is recommended to use exercise as a means of enhancement of students' selfesteem and mental health. Authors hope that the findings of the present research can be used by program planners and policy makers. Further studies should be conducted on the mechanism of action and continued effects of regular exercise on social groups.

\section{Acknowledgments}

Special thanks to all the students and administrative officials of the Islamic Azad University, Gorgan Branch who helped us conduct this research.

\section{Authors' Contribution}

The authors were involved in the study design, data collecion, interpretation of the results, and preparation of the manuscript.

\section{Funding/Support}

None received.

\section{Financial Disclosure}

The authors state that they have no financial interests to disclose.

\section{References}

1. Cooper, S. Self-steem enhancement with children and adolescent. New York: pergamon press. 2003.

2. Nasri A. Anthropological principles of the Quran. Press Jihad University.Tehran.2010:56.

3. Mcauley E, Mihalko SL, Bane SM. Exercise and self-esteem in middle-aged adults: multidimensional relationships and physical fitness and self-efficacy influences. J Behav Med. 1997; 20(9): 67-83.

4. Mann M, Hosman CM, Schaalma HP, de VriesNK.Self-esteem in a broad spectrum approach for mental health promotion. Health Educ Res. 2004; 19(4): 357-72.

5. Pate RR, Health GW, Dowda M, Trost SG. Associations between physical activity and other health behaviors in a representative sample of U.S. adolescents. Am J Public Health. 1996;86(11):1577-81.

6. Heath GW, Pratt M, Warren CW, Kann L. Physical activity patterns in American high school students: results from the 1990. Youth risk behavior survey. Arch Pediatr Adolesc Med. 1994;148(11):1131-6.

7. Alfermann D, Stoll O. Effects of physical exercise on self concept and well-being. Int J Sport Psychol. 2000;30:47-65.

8. Ghafari F, Fotokian Z, Mazloom R. Impact aerobic exercise program on nursing students' self-esteem. J Babol University Med Sci. 2008;9(1):52-57.

9. Sonwany, D R., Sharma. Physical activity and mental health. J exercise sci. 2007;7:131-146.

10. Spence, John. C- McGannon, Kerry - Poon, Pauline. "The effect of exercise on global self - esteem. University of Alberta". Journal of sport and exercise psychology. 2005;27:311-334.

11. Weiss, MR. Weiss, DM and Klint, KA. The relationship between self-esteem and performance in competitive youth gymnastics. Journal of sport and exercise psychology. 2008;11:444-51.

12. Gabriel, MJ and Perkins. Psychological skills and exceptional athletic performance". The sport psychologist. 2006;1:181-99.

13. Smith BL, Handley P, Eldredge DA. Sex differences in exercise motivation and body-image satisfaction among college students. Percept Mot Skills. 1998;86(2):723-32. 
14. Walters ST, Martin JE. Does aerobic exercise really enhance self-esteem in children? A prospective evaluation in 3rd-5th graders. J Sport Behav. 2000;23(1):51-60.

15. Robert W. Stretching/toning, aerobic exercise increase older adults' self-esteem. J Behav Med. 2005;28(4):385-94

16. Sedaghat P. Relationship between self-esteem and discipline of Students School of nursing and Midwifery zanjan._Proceedings of the National Congress of Nursing and Midwifery, 2005.

17. Mcauley E, Mihalko SL, Bane SM. Exercise and self-esteem in middle-aged adults: multidimensional relationships and physical fitness and self-efficacy influences. J Behav Med. 1997;20(9):67-83.

18. Asci Fh. the effect of physical fitness training on trait anxiety and physical seifconcept of femal university students. Psychology of sport and Exercise. 2002;4(3):255-64.

19. Thomas MB. Long term effects of aerobic exercises on psychological outcomes. Preventive Medicine. 1999; 28:75-85

20. Crozhdeh M, Mazloom R, Ebrahimi A, Behnam H. Impact aerobic exercise program on self-esteem healthcare workers. Journal of Mashhad School of Nursing and Midwifery.2003;5(17):29-35.

21. Saadatmehr R, Nourozi K, Khaledi N, Bakhshian F, Rezasoltani P. The effect of an aerobic training program on physical self-concept and self-esteem of nurses.2014;1(1):41-50.

22. Samadi S. Comparison of self-esteem and its relationship with psychological problems of Guilan University-(Ms Thesis)- Allameh Tabatabai University in Tehran 1994.

23. Bahaeloo-Horeh S, Assari S. Students experience self-esteem improvement during mountaineering. Wilderness \& Environmental Medicine. 2008;19(3):181-185.

24. Fagin L, Brown D, Bartlett H, Leary J, Carson J. The Claybury Community Psychiatric Nurse Stress Study: is it more stressful to work in hospital or the community? J Adv Nurs. 1995;22(2):347-58.

25. Gholamzadeh S, Sharif F, Rad FD. Sources of occupational stress and coping strategies among nurses who are working in Admission and Emergency Department in Hospitals affiliated to Shiraz University of Medical Sciences, Iran. Iran J Nurs Midwifery Res. 2011;16(1):42-7.

26. Whitesell NR, Mitchell CM, Spicer P. A longitudinal study of selfesteem, cultural identity, and academic success among American Indian adolescents. Cultur Divers Ethnic Minor Psychol. 2009;15(1):38-50.

27. Booth MZ, Gerard JM. Self-esteem and academic achievement: a comparative study of adolescent students in England and the United States. Compare. 2011;41(5):629-48.

28. Assari S. Additive Effects of Anxiety and Depression on Body Mass Index among Blacks: Role of Ethnicity and Gender. Int Cardiovasc Res J. 2014;8(2):44-51.

29. Assari S. The link between mental health and obesity: role of individual and contextual factors. Int J Prev Med. 2014;5(3):247-9.

30. Assari S. Association between obesity and depression among American Blacks: Role of ethnicity and gender. Journal of Racial and Ethnic Health Disparities. 2014;1(1):36-44.

31. Assari, S, Caldwell CH. Gender and ethnic differences in the association between obesity and depression among black adolescents. Journal of Racial and Ethnic Health Disparities. 2015;2(1):1-13.

32. Morgen CS, Sørensen TI. Obesity: global trends in the prevalence of overweight and obesity. Nat Rev Endocrinol. 2014;10(9):513-4.

33. Wasserman D, Cheng QI, Jiang GX. Global suicide rates among young people aged 15-19. World Psychiatry. 2005;4(2):114.

34. Kessler RC, Berglund P, Borges G, Nock M, Wang PS. Trends in suicide ideation, plans, gestures, and attempts in the United States, 1990-1992 to 2001-2003. JAMA. 2005;293(20):2487-95.

35. Bridge JA, Greenhouse JB, Weldon AH, Campo JV, Kelleher KJ. Suicide trends among youths aged 10 to 19 years in the United States, 1996-2005.JAMA. 2008;300(9):1025-6.

36. Anderson LM, Quinn TA, Glanz K, Ramirez G, Kahwati LC, Johnson DB, Buchanan LR, Archer WR, Chattopadhyay S, Kalra GP, Katz DL; Task Force on Community Preventive Services. The effectiveness of worksite nutrition and physical activity interventions for controlling employee overweight and obesity: a systematic review. Am J Prev Med. 2009;37(4):340-57.

37. Fonseca-Junior SJ, Sá CG, Rodrigues PA, Oliveira AJ, FernandesFilho J. Physical exercise and morbid obesity: a systematic review. Arq Bras Cir Dig. 2013;26 Suppl 1:67-73.

38. Rosenbaum S, Tiedemann A, Sherrington C, Curtis J, Ward PB. Physical activity interventions for people with mental illness: a systematic review and meta-analysis. J Clin Psychiatry. 2014;75(9):964-74.

39. Janssen I, Leblanc AG. Systematic review of the health benefits of physical activity and fitness in school-aged children and youth. Int J Behav Nutr Phys Act. 2010;7:40.

40. Vanderweele TJ, Hong G, Jones SM, Brown JL. Mediation and spillover effects in group-randomized trials: a case study of the 4Rs educational intervention. J Am Stat Assoc. 2013;108(502):469-82.
41. Strain PS, Shores RE, Kerr MM. An experimental analysis of "spillover" effects on the social interaction of behaviorally handicapped preschool children. J Appl Behav Anal. 1976;9(1):31-40.

42. de Heer HD, Koehly L, Pederson R, Morera O. Effectiveness and spillover of an after-school health promotion program for Hispanic elementary school children. Am J Public Health. 2011;101(10):190713.

43. Warburton DE, Nicol CW, Bredin SS. Health benefits of physical activity: the evidence. CMAJ. 2006;174(6):801-9.

44. Smitherman TA, Kendzor DE, Grothe KB, Dubbert PM. State of the art review: Promoting physical activity in primary care settings: A review of cognitive and behavioral strategies. American Journal of Lifestyle Medicine. 2007;1(5):397-409.

45. Iverson DC, Fielding JE, Crow RS, Christenson GM. The promotion of physical activity in the United States population: the status of programs in medical, worksite, community, and school settings.Public Health Rep. 1985;100(2):212-24

46. No authors listed. Guidelines for school and community programs to promote lifelong physical activity among young people. Centers for Disease Control and Prevention. MMWR Recomm Rep. 1997;46(RR-6):1-36.

47. Ellis KR, Caldwell CH, Assari S, De Loney EH. Nonresident AfricanAmerican fathers' influence on sons' exercise intentions in the fathers and sons program. Am J Health Promot. 2014;29(2):89-98.

48. Baghurst T, Kelley BC. An examination of stress in college students over the course of a semester. Health Promot Pract. 2014;15(3):438 47. 